\title{
Mối quan hệ giữa phong cách lãnh đạo và sức khỏe thể chất, tâm lý và xã hội của người lao động làm việc tại các đơn vị thuộc UBND quận Bình Thủy, Thành Phố Cần Tho
}

\section{The relationship between management style and physical, psychological and social well-being of employees working at the People's Committee of Binhthuy District - Can Tho City}

\author{
Nguyễn Văn Tuấn ${ }^{*}$, Nguyễn Chu Mạnh ${ }^{2}$, Nguyễn Hữu Dũng ${ }^{3}$ \\ ${ }^{1}$ UBND Quận Bình Thủy, Thành phố Cần Thơ, Việt Nam \\ ${ }^{2}$ Công ty Cổ phần Tập đoàn Erica, Việt Nam \\ ${ }^{3}$ Trường Đại học Kinh tế Thành phố Hồ Chí Minh, Việt Nam \\ *Tác giả liên hệ, Email: ksngtuan@yahoo.com.vn
}

\section{THÔNG TIN}

DOI:10.46223/HCMCOUJS. econ.vi.14.2.1506.2019

Ngày nhận: 08/03/2019

Ngày nhận lại: 10/04/2019

Duyệt đăng: 10/04/2019

Tù khóa:

nhân viên hành chính, phong cách quản trị, tâm lý và xã hội, tình trạng thể chất

Keywords:

management style, physical, psychological and social health, public officials

\section{TÓM TẮT}

Nghiên cứu được thực hiện nhằm xem xét mối quan hệ giữa phong cách lãnh đạo của những người lãnh đạo trực tiếp tại các đơn vị hành chính quận Bình Thủy-Thành phố Cần Thơ. Các phong cách lãnh đạo (độc tài, dân chủ, gia trưởng, tự do) và sức khỏe thể chất, tâm lý và xã hội được phân tích định lượng dựa trên thông tin từ các bảng phỏng vấn. Tổng số có 193 người lao động tại các đơn vị hành chính quận trả lời. Kết quả nghiên cứu cho thấy các nhà lãnh đạo tại các đơn vị thể hiện phong cách dân chủ, và tiếp theo đó là phong cách tự do. Về khía cạnh sức khỏe của người lao động, kết quả cho thấy người lao động có tình trạng tốt về sức khỏe thể chất, tâm lý và xã hội. Ngoài ra, nghiên cứu đã khẳng định có mối quan hệ mạnh và tích cực giữa phong cách dân chủ và 3 khía cạnh sức khỏe của người lao động.

\section{ABSTRACT}

This study set out to investigate the relationship between management style practiced by managers and employees' physical, psychological and social well-being in administrative units of Binh Thuy District People's Committee - Can Tho City. The types of management style (autocratic, democratic, paternalistic and laissezfaire) and employee's well-being were measured quantitatively through a set of customized questionnaires. A total of 193 respondents from the district administrative units completed the given questionnaire. The result revealed that the unit managers practiced democratic management style as the first and followed by 
the laissez-faire management style. Regarding the employees' wellbeing, the employees working under unit managers are healthy physically, psychologically, and socially. In addition, there is a strong and positive relationship between democratic style with the three aspects of employees' well-being.

\section{Giới thiệu}

Đổi mới phong cách làm việc và lãnh đạo đơn vị là một trong những yêu cầu quan trọng trong cải cách hành chính của các cơ quan quản lý nhà nước hiện nay. Chính vì vai trò quan trọng đó mà nhiều thập kỷ qua, phong cách lãnh đạo luôn được các nhà quản trị, nghiên cứu kinh tế tìm hiểu và đưa ra nhiều giải pháp phát triển. Hành vi của nhà lãnh đạo còn ảnh hưởng tích cực đến chất lượng đời sống công việc, và hiệu quả quản lý nguồn nhân lực (Ibrahim \& AlTaneiji, 2013; Barzegar, Afzal, Tabibi, \& Delgoshaei, 2012). Người lãnh đạo hiệu quả là người biết vận dụng linh hoạt phong cách tương ứng cho từng tình huống xảy ra. Phong cách lãnh đạo ảnh hưởng đến nhân viên trên nhiều phương diện khác nhau đặc biệt là sức khỏe và tinh thần.

Trong thời gian gần đây, theo ghi nhận của lãnh đạo cấp thành phố nhiều cán bộ, công chức làm việc tại các cơ quan Phòng ban và Ủy ban nhân dân (UBND) các Phường thuộc Quận Bình Thủy Thành phố (TP) Cần Thơ có nhiều biểu hiện chậm trễ, thiếu nhiệt huyết, làm ảnh hưởng đến không khí và hiệu suất, hiệu quả trong giải quyết công việc. Lý thuyết và thực tiễn điều cho thấy nhân viên là sức mạnh của một tổ chức. Trong những lúc khó khăn, sức mạnh ấy lại càng có vai trò quan trọng. Tuy nhiên, tinh thần và cách quản lý của người đứng đầu có ảnh hưởng lớn đến sức khỏe tâm lý cũng như hiệu suất, hiệu quả làm việc của cấp dưới. Câu hỏi đặt ra là trong tình hình của địa phương phong cách lãnh đạo có ảnh hưởng thế nào đến nhân viên, là động lực chính để tác giả thực hiện đề tài "Mối quan hệ giũa phong cách lãnh đạo và tình trạng thể chất, tâm lý và xã hội của cán bộ, công chức làm việc tại các co quan thuộc UBND Quận Bình Thủy, Thành phố Cần Tho"” trong năm 2016. Mục đích để nắm bắt và hiểu biết được phong cánh chính của lãnh đạo đơn vị hiện nay là phong cách nào và ảnh hưởng của phong cách đó đến nhân viên ra sao.

Mục tiêu nghiên cứu chính của đề tài là xem xét mối quan hệ và ảnh hưởng của phong cách lãnh đạo đến tình trạng thể chất, tâm lý và xã hội của cán bộ công chức cấp dưới (sau đây gọi là nhân viên hoặc người lao động) tại Quận Bình Thủy, TP. Cần Thơ, nhằm đề xuất các biện pháp cải thiện và xây dựng phong cách nhà lãnh đạo năng động và hiệu quả. Mối quan hệ được xem xét thông qua hệ số tương quan Pearson, phân tích hồi quy tuyến tính OLS, và so sánh điểm trung bình của các đánh giá cảm nhận thông qua kiểm định t.

\section{Cơ sở lý thuyết và thực tiễn}

\subsection{Khái niệm quản trị và lãnh đạo}

"Quản trị" và "lãnh đạo" là hai thuật ngữ xuất hiện thường xuyên trong nhiều tài liệu và thậm chí chúng được sử dụng thay thế cho nhau. Trong thực tế, khó có thể phân biệt một nhà quản trị và một nhà lãnh đạo vì đôi khi họ thực hiện cả hai chức năng quản trị và lãnh đạo. 
Kotter (1990) cho rằng lãnh đạo và quản lý là hai phạm trù khác nhau, tuy nhiên chúng bổ sung cho nhau trong các hành động của một tổ chức. Theo tác giả này, thì lãnh đạo có xu hướng là giải quyết những vấn đề thay đổi, trong khi đó quản trị tập trung giải quyết các vấn đề phức hợp.

\subsection{Phong cách lãnh đạo}

Theo Nguyen (2011) thì "Phong cách lãnh đạo của một cá nhân là dạng hành vi người đó thể hiện khi thực hiện các nỗ lực ảnh hưởng tới hoạt động của những người khác theo nhận thức của đối tượng”. Phong cách lãnh đạo có thể được xác định theo những đặc điểm, triết lý lãnh đạo, và một tập hợp những kỹ năng quản lý tiêu biểu cho mỗi phong cách. Các đặc điểm của phong cách nhấn mạnh vào cách thức mà người lãnh đạo đặt vào công việc và con người. Các kỹ năng quản lý rất quan trọng vì các kỹ năng này có thể thích hợp trong từng tình huống (Warrick, 1981). Phong cách lãnh đạo nào sẽ mang lại nhiều tác dụng cho một người và cho tổ chức là một câu hỏi đặt ra cho cả cá nhân và tổ chức. Để có thể trả lời câu hỏi này thì tốt nhất cần phải biết rằng có nhiều phong cách khác nhau để lựa chọn, và để có thể phát triển năng lực lãnh đạo của bản thân, thì cần thiết học tập và phát triển nhiều phong cách khác nhau.

\subsubsection{Phong cách lãnh đạo độc tài (Autocratic or authoritarian leadership)}

Theo Warrick (1981) thì nhà lãnh đạo độc tài không nhấn mạnh và quan tâm đến thái độ, hành vi và quyết định của người khác. Nhà lãnh đạo độc đoán tập trung quyền hành và các quyết định vào bản thân họ. Họ cho rằng họ có quyền lực và chịu hoàn toàn trách nhiệm, yêu cầu người khác làm lại điều gì mà bản thân họ không thích, không đúng theo mệnh lệnh đã ban hành. Nhân viên phải làm việc cật lực theo những qui định và yêu cầu để tránh phải nhận những hình phạt. Do đó các quyết định của lãnh đạo và cách thức hoàn thành nhiệm vụ của nhân viên rất ít sáng tạo.

\subsubsection{Phong cách lãnh đạo dân chủ (Democratic leadership)}

Nhà lãnh đạo dân chủ phân quyền cho những người khác, thường tham khảo ý kiến của nhiều người khuyến khích nhân viên tham gia, có ý kiến trong việc lập kế hoạch và các chính sách, dù họ vẫn là người ra quyết định cuối cùng. Những người dưới quyền được chỉ dẫn và động viên tham gia vào quá trình đưa ra quyết định, thay vì mệnh lệnh và cưỡng bức thi hành. Phong cách lãnh đạo này hướng về cả việc thực hiện và con người. Tuy nhiên, phong cách dân chủ cũng gặp phải khó khăn trong những tình huống khi ý kiến quá nhiều mà không tìm ra được một quyết định công bằng và hợp lý.

\subsubsection{Phong cách lãnh đạo tụ do (Laissez-faire hoặc Free-rein leadership)}

Nhà lãnh đạo theo phong cách tự do rất ít tham gia vào việc ra quyết định cũng như chỉ dẫn cho cấp dưới. Những người này thường cho phép cấp dưới tự quyết định theo ý mình mặc dù vẫn chịu trách nhiệm đối với kết quả cuối cùng. Các nhà lãnh đạo đã chuyển những trách nhiệm hình thành quyết định của mình sang nhân viên và chỉ đóng một vai trò nhỏ trong việc quản lý (Warrick, 1981). Phong cách này phù hợp khi những người cấp dưới có khả nãng và động lực để đưa ra quyết định của chính mình. Hoặc trong tình huống không cần sự phối hợp trung tâm. 


\subsubsection{Phong cách lãnh đạo gia trương (Paternalistic leadership)}

Phong cách lãnh đạo gia trưởng dựa vào những giá trị như lòng trung thành của một người đối với người lãnh đạo và tuân thủ lệnh không một chất vấn nào (Ekin \& Terri, 2008). Nhà lãnh đạo theo phong cách gia trưởng giả định rằng chức năng và vai trò của mình như là người cha đối với cấp dưới. Mối quan hệ giữa nhà lãnh đạo và nhân viên cũng tương tự như mối quan hệ giữa người đứng đầu hộ gia đình với các thành viên trong hộ. Nhà lãnh đạo gia trưởng sẽ không thành công khi quy mô của tổ chức lớn nếu họ không biết học cách chia sẻ quyền lực (Bennis, 2013).

\subsection{Khái niệm sức khỏe thể chất, tinh thần và xã hội}

Tổ chức y tế thế giới WHO - (World Health Organization) định nghĩa 'Sức khỏe là trạng thái tốt hoàn toàn về thể chất, tinh thần và tâm lý xã hội, chứ không phải là chỉ không có bệnh tật, yếu đuối'.

\subsubsection{Sức khỏe thể chất}

Sức khỏe về thể chất là một điều quan trọng trong hạnh phúc của một người và là một trong những khía cạnh khác nhau về sức khỏe có thể dễ thấy nhất. Một trong những dấu hiệu rõ ràng và nghiêm trọng nhất cho thấy một người không khỏe mạnh được phản ảnh qua sức khỏe thể chất. Sức khỏe về thể chất có thể phản ảnh qua nhiều khía cạnh: hoạt động thể chất, dinh dưỡng và ăn kiêng, uống thức uống có cồn và nghiện ngập, kiểm tra sức khỏe định kỳ, nghỉ ngơi và giấc ngủ.

\subsubsection{Súc khoẻ xã họi}

Sức khỏe xã hội là khả năng để tạo dựng và gìn giữ các mối quan hệ lành mạnh với những người khác. Điều này thể hiện ở sự tự nhiên, thoải mái trong các mối quan hệ chằng chịt, phức tạp giữa các thành viên: gia đình, nhà trường, bạn bè, xóm làng, nơi công cộng, trong một

tổ chức... Càng hòa nhập với mọi người, được mọi người đồng cảm, yêu mến càng có sức khỏe xã hội tốt và ngược lại.

Một người được xem là có một sức khỏe xã hội tốt có đặc điểm: nhìn nhận được quan trọng của sự gắn kết vào xã hội; có thể trợ giúp người thân, bạn bè khi cần thiết, và cũng có thể cần đến sự trợ giúp của người khác trong những lúc cần thiết; không thiên vị, không có định kiến, phân biệt chủng tộc, phân biệt giới tính; biết lắng nghe những người khác, diễn tả cảm nghĩ của mình theo hướng tốt, hành động theo một cách đầy trách nhiệm trước những người khác.

\subsubsection{Khỏe manh về tâm lý}

Sự khỏe mạnh về tâm lý hay sức khỏe tâm lý là một tình trạng tốt về tinh thần, tình cảm, xã hội và tâm hồn. Đây là cách thức mà mọi người nhìn vào chính mình và là cách thức mà mọi người giải quyết trong những tình huống căng thẳng, giúp phân biệt một người có khỏe mạnh về mặt tâm lý hay không. Một phần của sức khỏe tâm lý là sức khỏe về tinh thần. Cơ sở của sức mạnh tinh thần là sự thăng bằng và hài hoà trong hoạt động tinh thần giữa lý trí và tình cảm. Thông thường thì sự khỏe mạnh về tinh thần đi cùng với sự khỏe mạnh về cảm xúc. Một người 
được xem là không khỏe mạnh về cảm xúc khi họ có cách cư xử trong một tình huống nào đó với tình trạng không thể kiểm soát, không phù hợp, và mang tính cực đoan.

\subsection{Các nghiên cúu liên quan}

Nghiên cứu của Tran và Nguyen (2007) cho thấy phong cách lãnh đạo mới về chất có ảnh hưởng mạnh đến văn hóa, lòng trung thành và kết quả làm việc theo nhận thức của nhân viên. Trong nghiên cứu về ảnh hưởng của phong cách lãnh đạo đến sự gắn kết với tổ chức, Bui (2011) đã cho thấy các phong cách lãnh đạo ân cần, lãnh đạo có xu hướng thiên về nhiệm vụ, lãnh đạo khuyến khích sáng tạo có ảnh hưởng đến lòng trung thành của nhân viên.

Abu Mansor, Choon, Mohamed, và Ishak (2012) nghiên cứu tìm hiểu ảnh hưởng của các phong cách lãnh đạo (độc tài, dân chủ, tự do và gia trưởng) đến phúc lợi (sức khỏe thể chất, tâm lý và xã hội) của nhân viên. Kết quả của nghiên cứu này cho thấy, các nhà quản trị tại đây thực hành nhiều nhất theo phong cách lãnh đạo gia trưởng, các nhân viên khỏe mạnh về thể chất, tâm lý và xã hội. Nghiên cứu này cũng chính là cơ sở để tác giả đề xuất mô hình nghiên cứu được nêu chi tiết trong phần 3 .

Trong một nghiên cứu về mối quan hệ giữa phong cách lãnh đạo và văn hóa đã cho thấy phong cách lãnh đạo rất đa dạng và bị ảnh hưởng bởi văn hóa môi trường. Các nhà lãnh đạo được cảnh báo phải đặc biệt chú ý đến văn hóa đặc trưng của mỗi nơi để có phong cách quản lý phù hợp (Taleghani, Salmani, \& Taatian, 2010). Ngoài ra, các phong cách lãnh đạo có sức ảnh hưởng rất khác nhau đến nhân viên. Phong cách lãnh đạo ảnh hưởng đến mức độ hiếp đáp trong đơn vị và sự hà hiếp này làm tinh thần của nhân viên sa sút (Hoel \& Cooper, 2000).

Phong cách lãnh đạo chuyển đổi có ảnh hưởng tích cực lên tâm lý của nhân viên. Việc tăng cường phong cách lãnh đạo này sẽ làm tăng thêm phúc lợi cho nhân viên (Nielsen, Randall, Yarker, \& Brenner, 2008). Beehr và Gupta (1987) cũng kết luận rằng phong cách lãnh đạo truyền thống tạo ra nhiều áp lực hơn, trong khi đó phong cách dân chủ làm nhân viên có thái độ tích cực. Dưới sự quản lý của nhà lãnh đạo có phong cách chuyển đổi thì sự thỏa mãn và kết quả làm việc của nhân viên tốt hơn so với phong cách chuyển giao (Rus, 2012). Tất cả những nghiên cứu này đều cho thấy phong cách lãnh đạo ảnh hưởng đến nhân viên cả về sức khỏe thể chất, tinh thần, sự cam kết và hiệu quả trong công việc.

Hành vi của nhà lãnh đạo còn ảnh hưởng tích cực đến chất lượng đời sống, công việc và hiệu quả quản lý nguồn nhân lực (Ibrahim \& Al-Taneiji, 2013). Khi nhân viên được thỏa mãn về phúc lợi thì họ sẽ mang lại cho tổ chức với năng suất làm việc cao hơn. Như vậy, không có một phong cách lãnh đạo nào là tốt nhất mà chỉ có phong cách lãnh đạo phù hợp với môi trường, tình huống cụ thể.

\section{Phương pháp thực hiện nghiên cứu}

\subsection{Khung phân tích}

Từ cơ sở lý thuyết và nghiên cứu về ảnh hưởng của phong cách lãnh đạo đến sức khỏe tâm lý, xã hội và thể chất trình bày trong phần 2.4, tác giả đã áp dụng mô hình của Abu Mansor và cộng sự (2012) để nghiên cứu vào tình huống cụ thể tại cơ quan quản lý nhà nước Quận Bình Thủy như sau: 


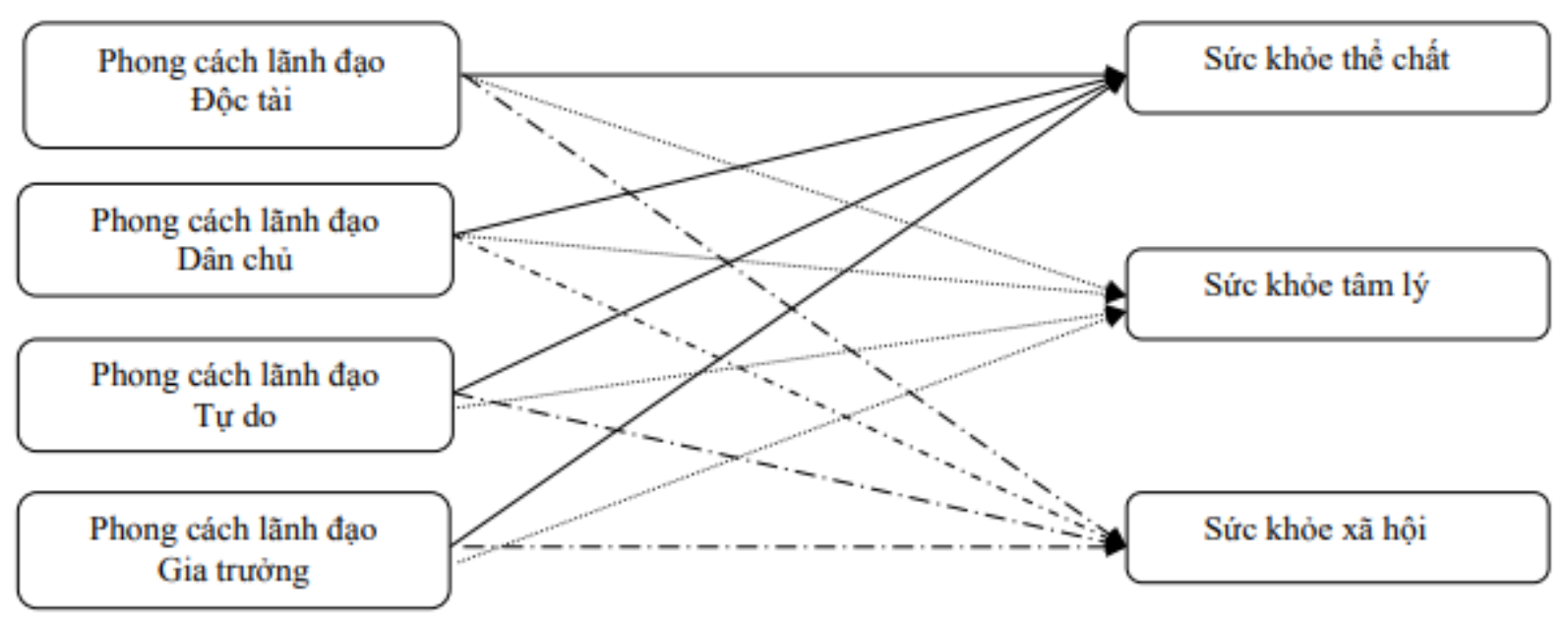

Hình 1. Mô hình nghiên cứu (Abu Mansor et al., 2012)

Theo mô hình này, có 4 phong cách lãnh đạo được xem xét sự ảnh hưởng của từng phong cách đến sức khỏe thể chất, sức khỏe tâm lý và sức khỏe xã hội của nhân viên là: phong cách độc tài, phong cách dân chủ, phong cách tự do và phong cách gia trưởng.

\subsection{Thang do}

Thang đo của Abu Mansor và cộng sự (2012) đã phát triển, kiểm định và áp dụng trong nghiên cứu tại Malaysia, được tác giả sử dụng trong đề tài này. Đề tài mang tính chất nghiên cứu ứng dụng, do vậy tất cả các câu hỏi nguyên bản trong nghiên cứu và khảo sát của $\mathrm{Abu}$ Mansor và cộng sự (2012) được dịch từ tiếng Anh sang tiếng Việt. Bước tiếp theo là kiểm tra lại mức độ trong sáng về tiếng Việt của các câu hỏi thông qua thảo luận với một số cán bộ lãnh đạo tại quận Bình Thủy, và các cán bộ nghiên cứu tại Trường Đại học Kinh tế Thành phố Hồ Chí Minh.

Thang đo phong cách lãnh đạo: mỗi thang đo cho mỗi phong cách gồm 4 biến quan sát (items) đại diện cho đặc điểm của từng phong cách lãnh đạo, được đo lường bằng thang đo Likert 5 mức độ, thể hiện ý kiến của người trả lời từ rất không đồng ý (giá trị 1) đến hoàn toàn đồng ý (giá trị 5); giá trị 3 là trung lập.

Thang đo sức khỏe thể chất, sức khỏe tâm lý, sức khỏe xã hội: mỗi thang đo gồm 5 biến quan sát (item) đại diện cho các đánh giá cảm nhận về các tình trạng sức khỏe, được đo lường bằng thang đo Likert 5 mức độ, thể hiện ý kiến của người trả lời về mức độ thường xuyên gặp phải. Mức 1 (A: rất thường xuyên), mức $2(\mathrm{~F}$ : thường xảy ra), mức $3(\mathrm{O}$ : bình thường), mức 4 ( $\mathrm{S}$ : ít khi), đến mức 5 ( $\mathrm{N}$ : chưa bao giờ).

\subsection{Bảng phỏng vấn và thu thập số liệu}

Bảng phỏng vấn được xây dựng để thu thập số liệu bao gồm 2 phần: phần thứ nhất là các câu hỏi trong thang đo về 4 phong cách lãnh đạo; phần thứ 2 là các câu hỏi trong thang đo liên quan đến sức khỏe thể chất, tâm lý và xã hội của người được phỏng vấn; và phần 3 là các thông tin về đặc điểm nhân chủng học, kinh tế-xã hội của người được phỏng vấn. 
Đề tài áp dụng phương pháp chọn mẫu phi xác suất theo hạn ngạch (quota) do điều kiện giới hạn về thời gian và tài chính, và cũng mới chỉ là một nghiên cứu ứng dụng thăm dò. Trên cơ sở bộ máy tổ chức hiện nay của cơ quan quản lý hành chính tại quận Bình Thủy bao gồm bộ phận quản lý nhà nước cấp quận và cấp phường, tác giả đã chọn khảo sát tổng số 20 đơn vị: toàn bộ Văn phòng UBND quận, 11 phòng chức năng và 8 UBND phường. Số quan sát tại mỗi địa bàn là 10 nhân viên. Tổng số mẫu dự kiến là 200 nhân viên. Thời gian tiến hành khảo sát tại 20 địa điểm là tháng 7 năm 2016. Tổng số quan sát sau khi gạn lọc, kiểm tra mức độ hoàn chỉnh các mục hỏi của từng nhân viên, loại bỏ các quan sát (nhân viên) có số liệu trống (missing data) quá nhiều trên 10 mục khảo sát thì số quan sát sau cùng của mẫu là $n=193$ được sử dụng là nguồn số liệu sơ cấp chính yếu của nghiên cứu.

\subsection{Cách thức phân tích}

Kỹ thuật phân tích chủ yếu được sử dụng trong đề tài là phân tích thăm dò, thống kê mô tả. Thứ nhất, để phân tích các phong cách lãnh đạo và tình hình sức khỏe của nhân viên, đề tài sử dụng phương pháp bình quân gia quyền tính điểm số cho từng biến quan sát trong thang đo. Sau đó tính trung bình điểm số cho từng thang đo. Phong cách có điểm cao nhất chính là phong cách mà các nhà lãnh đạo thể hiện nhiều nhất trong quá trình điều hành đơn vị. Tương tự như vậy trung bình điểm số của các thang đo về sức khỏe để đánh giá tổng quát tình trạng thể chất, tâm lý và xã hội của các nhân viên. Điểm số càng cao thể hiện tình trạng sức khỏe càng tốt. Thứ 2 là kiểm định độ tin cậy hay mức độ nhất quán bên trong (internal consistency) của từng thang đo bằng hệ số Cronbach's Anpha. Hệ số Cronbach's Anpha $\geq 0.6$ là thang đo có thể chấp nhận. Thứ 3 là sử dụng hệ số tương quan Pearson và phân tích hồi quy tuyến tính OLS để xem xét mối quan hệ của các phong cách lãnh đạo đến sức khỏe thể chất, tâm lý và xã hội của nhân viên. Sau cùng là so sánh các số trung bình về ảnh hưởng của các phong cách lãnh đạo đến sức khỏe thể chất, tâm lý, xã hội giữa hai hoặc các nhóm đối tượng thông qua kiểm định t.

Mô hình hồi quy ảnh hưởng của các phong cách lãnh đạo đến sức khỏe thể chất, tâm lý, xã hội của nhân viên nhằm kiểm định 3 giả thuyết sau đây:

H1: Phong cách lãnh đạo độc tài (ĐT), gia trương (GT), dân chủ (DC) và tụ do (TD) có ảnh hưởng khác nhau đến sức khỏe thể chất của nhân viên

H2: Phong cách lãnh đạo độc tài, gia trương, dân chủ và tụ do có ảnh hưởng khác nhau đến sức khỏe tâm lý của nhân viên

H3: Phong cách lãnh đạo độc tài, gia trưởng, dân chủ và tụ do có ảnh hưởng khác nhau đến sức khỏe xã hội của nhân viên

$$
\begin{aligned}
& \text { THECHAT }=\beta_{0}+\beta_{1} \text { ĐT }+\beta_{2} \mathrm{DC}+\beta_{3} \mathrm{GT}+\beta_{4} \mathrm{TD}+\varepsilon_{1} \\
& \mathrm{TAMLY}=\beta_{0}+\beta_{1} \mathrm{ÐT}+\beta_{2} \mathrm{DC}+\beta_{3} \mathrm{GT}+\beta_{4} \mathrm{TD}+\varepsilon_{2} \\
& \mathrm{XAHOI}=\beta_{0}+\beta_{1} \mathrm{ÐT}+\beta_{2} \mathrm{DC}+\beta_{3} \mathrm{GT}+\beta_{4} \mathrm{TD}+\varepsilon_{3}
\end{aligned}
$$

Trong đó:

- THECHAT, TAMLY, XAHOI: là 3 biến số phụ thuộc, thể hiện sức khỏe thể chất, tâm lý và xã hội của nhân viên; ĐT, DC, GT, TD là ký hiệu các biến độc lập theo thứ tự: độc tài, dân chủ, gia trưởng và tự do; 
- $\beta_{0}$ là hệ số góc; $\beta_{1}, \beta_{2}, \beta_{3}, \beta_{4}$ là các hệ số hồi quy chưa chuẩn hóa trong mô hình;

- En: là sai số của mô hình.

Kiểm định mức độ phù hợp của mô hình bao gồm kiểm định $\mathrm{F}$, quan hệ đa cộng tuyến, và phân phối của phần dư.

\section{Kết quả nghiên cứu}

\section{1. Đặc điểm mẫu khảo sát}

Một số đặc điểm nhân chủng học và kinh tế xã hội của các nhân viên làm việc tại quận Bình Thủy được khảo sát trong mẫu $(\mathrm{n}=193)$ tóm lược như sau: tỷ lệ nữ chiếm $54,90 \%$, nam $45,10 \%$, và chủ yếu là dân tộc Kinh. Đối tượng phỏng vấn từ cấp phó phòng trở xuống có độ tuổi từ 40 trở xuống chiếm hơn $80 \%$ số nhân viên được khảo sát; $17 \%$ số nhân viên có độ tuổi lớn hơn 40 . Tình trạng gia đình của nhân viên đang sống cùng vợ/chồng chiếm $71 \%$ số quan sát, $25 \%$ trong số nhân viên khảo sát còn trẻ và chưa lập gia đình.

Trình độ học vấn của nhân viên được khảo sát tại Bình Thủy là khá cao, 87\% đã đạt trình độ đại học. Hơn $50 \%$ nhân viên đã làm việc tại các đơn vị từ năm năm trở lên, và $30 \%$ làm việc dưới 3 năm. Thu nhập bình quân hàng tháng của nhân viên từ cấp phó trở xuống là khá thấp, hơn $85 \%$ nhân viên có thu nhập dưới 5 triệu đồng/tháng.

\subsection{Phong cách lãnh đạo tại các đơn vị}

\subsubsection{Phong cách lãnh đạo độc tài}

Kết quả kiểm định thang đo có Cronbach's $\alpha=0,74$, hệ số tương quan biến tổng của các biến quan sát trong thang đo đều $\geq 0,3$, cho thấy độ tin cậy của thang đo.

\section{Bảng 1}

Mô tả các biến phong cách lãnh đạo độc tài

\begin{tabular}{|l|c|c|c|}
\hline & Trung bình & STD & Kiểm định-t \\
\hline $\begin{array}{l}\text { Lãnh đạo thường đưa ra quyét định mà không tham } \\
\text { khảo ý kiến của những người khác. }\end{array}$ & 2,64 & 1,11 & $-4,54 * * *$ \\
\hline $\begin{array}{l}\text { Nhân viên hiếu rằng không nên thắc mắc về phán } \\
\text { quyết của lãnh đạo vì lãnh đạo hiếm khi thay đổi } \\
\text { quyết định của mình một khi đã thực sự đam mê } \\
\text { một điều gì đó. }\end{array}$ & 2,88 & 1,03 & $-1,68^{*}$ \\
\hline $\begin{array}{l}\text { Lãnh đạo thúc ép nhân viên làm việc cật lực hơn, } \\
\text { ngay cả khi một vài nhân viên đã thực sự làm việc } \\
\text { rất vất vả. }\end{array}$ & 2,51 & 1,08 & $-6,36 * * *$ \\
\hline $\begin{array}{l}\text { Lãnh đạo thúc giục nhân viên làm việc nhiều hơn } \\
\text { để vượt qua những thành tích họ đã đạt được trước } \\
\text { đó. }\end{array}$ & 3,08 & 1,09 & $1,06 \mathrm{~ns}$ \\
\hline
\end{tabular}

Ghi chú: kiểm định $\mathrm{t}$ với giá trị $=3$. STD: độ lệch chuẩn

*,**,*** thể hiện mức có nghĩa thống kê theo thứ tự ở mức ý nghĩa $10 \%, 5 \%$, và $1 \%$

Nguồn: Kết quả phân tích dữ liệu của nhóm nghiên cứu 
Kết quả phân tích giá trị trung bình của bốn biến quan sát là 2,78 , cho thấy phong cách lãnh đạo độc tài không phổ biến tại các cơ quan hành chính của quận. Các biến quan sát được kiểm định $\mathrm{t}$ (với giá trị từ 3 ) khẳng định là nhân viên rất không đồng tình về những biến đã nêu. Nghĩa là lãnh đạo thường tham khảo ý kiến của những người khác trước khi đưa ra quyết định. Hoặc lãnh đạo không thúc ép nhân viên làm việc cật lực khi họ đã và đang làm rất vất vả.

\subsubsection{Phong cách lãnh đạo dân chủ}

Thang đo phong cách lãnh đạo dân chủ gồm 4 biến quan sát. Kết quả kiểm định thang đo có Cronbach's $\alpha=0,77$, hệ số tương quan biến tổng của các biến quan sát trong thang đo đều $\geq 0,3$, cho thấy độ tin cậy của thang đo. Kết quả phân tích giá trị trung bình của bốn biến quan sát là 3,59 , và bản thân từng biến cũng lớn hơn giá trị 3 cho thấy phong cách lãnh đạo dân chủ khá phổ biến tại các cơ quan hành chính của quận. Điều này là một điểm mạnh và cần phát huy tại cơ quan quản lý nhà nước.

\section{Bảng 2}

Mô tả các biến phong cách lãnh đạo dân chủ

\begin{tabular}{|l|c|c|c|}
\hline & Trung bình & STD & Kiểm định-t \\
\hline $\begin{array}{l}\text { Lãnh đạo luôn đưa ra quyết định bằng phương thức } \\
\text { biểu quyết. }\end{array}$ & 3,61 & 1,08 & $7,83^{*} * *$ \\
\hline $\begin{array}{l}\text { Lãnh đạo nhận được sự đồng ý của nhân viên trước } \\
\text { khi quyết định thay đồi bất kỳ điều gì về điều kiện } \\
\text { làm việc hoặc vai trò của nhân viên, dù sự thay đổi } \\
\text { đó chỉ xảy ra trong một ngày. }\end{array}$ & 3,50 & 0,97 & $7,17 * * *$ \\
\hline $\begin{array}{l}\text { Nhân viên luôn chất vấn những ý tưởng và chiến } \\
\text { lược của lãnh đạo đưo ra, vì nhân viên biết rằng họ } \\
\text { được lãnh đạo khuyến khích làm như vậy. }\end{array}$ & 3,39 & 0,99 & $5,50 * * *$ \\
\hline $\begin{array}{l}\text { Lãnh đạo phân công nhiệm vụ một cách công bằng } \\
\text { cho nhân viên của mình trong đơn vị. }\end{array}$ & 3,87 & 1,03 & $11,74 * * *$ \\
\hline
\end{tabular}

Ghi chú: kiểm định $\mathrm{t}$ với giá trị $=3$. STD: độ lệch chuẩn

*,**,*** thể hiện mức có nghĩa thống kê theo thứ tự ở mức ý nghĩa $10 \%, 5 \%$, và $1 \%$

Nguồn: Kết quả phân tích dữ liệu của nhóm nghiên cứu

\subsubsection{Phong cách lãnh đạo gia trưởng}

Kết quả kiểm định thang đo có Cronbach's $\alpha=0,71$, hệ số tương quan biến tổng của các biến quan sát trong thang đo đều $\geq 0,3$, cho thấy độ tin cậy của thang đo.

\section{Bảng 3}

Mô tả các biến phong cách lãnh đạo gia trưởng

\begin{tabular}{|l|c|c|c|}
\hline & Trung bình & STD & Kiểm định-t \\
\hline $\begin{array}{l}\text { Lãnh đạo sẵn sàng cho lời khuyên và động viên, trợ } \\
\text { giúp khi nhân viên cần ý kiến. }\end{array}$ & 3,22 & 0,94 & $3,30 * * *$ \\
\hline $\begin{array}{l}\text { Lãnh đạo có tham khảo ý kiến của nhiều người trước } \\
\text { khi đưa ra quyết định, nhưng những người này có xu } \\
\text { hướng là đồng ý, chấp thuận những ý định ban đầu } \\
\text { của lãnh đạo. }\end{array}$ & 3,08 & 1,02 & $1,13 \mathrm{~ns}$ \\
\hline
\end{tabular}




\begin{tabular}{|l|c|c|c|}
\hline & Trung bình & STD & Kiểm định-t \\
\hline $\begin{array}{l}\text { Nhân viên trong cơ quan xem lãnh đạo đơn vị chỉ là } \\
\text { người lãnh đạo (người truyền cảm hứng và nhiệt } \\
\text { huyết) chứ không phải là người quản lý (điều hành, } \\
\text { củng cố, duy trì). }\end{array}$ & 3,06 & 1,01 & $0,85 \mathrm{~ns}$ \\
\hline $\begin{array}{l}\text { Lãnh đạo 'giống' như hình ảnh một người cha đối } \\
\text { với những đứa con (nhân viên) trong cơ quan, nơi } \\
\text { mà lãnh đạo có trách nhiệm chăm sóc họ (nhân viên). }\end{array}$ & 3,13 & 1,16 & $1,61 \mathrm{~ns}$ \\
\hline
\end{tabular}

Ghi chú: kiểm định $\mathrm{t}$ với giá trị = 3. STD: độ lệch chuẩn

*,**,*** thể hiện mức có nghĩa thống kê theo thứ tự ở mức ý nghĩa $10 \%, 5 \%$, và $1 \%$

Nguồn: Kết quả phân tích dữ liệu của nhóm nghiên cứu

Kết quả phân tích giá trị trung bình của bốn biến quan sát là 3,13, và bản thân từng biến hầu hết là có giá trị 3 cho thấy nhân viên còn đang có ý kiến trung lập về phong cách lãnh đạo gia trưởng. Lãnh đạo tại các đơn vị không 'giống' như hình ảnh một người cha đối với những đứa con (nhân viên) trong cơ quan, nơi mà lãnh đạo có trách nhiệm chăm sóc họ (nhân viên).

\subsubsection{Phong cách lãnh đạo tụ do}

Kết quả kiểm định thang đo có Cronbach's $\alpha=0,78$, hệ số tương quan biến tổng của các biến quan sát trong thang đo đều $\geq 0,3$, cho thấy độ tin cậy của thang đo. Giá trị trung bình của bốn biến quan sát là 3,40 , và giá trị riêng của từng biến quan sát đều lớn hơn 3 , nói lên rằng nhân viên đánh giá là các lãnh đạo đơn vị của họ có một phong cách lãnh đạo có sự tôn trọng ý kiến và cách làm việc, suy nghĩ độc lập của nhân viên. Nói cách khác, hàm ý nổi bật rút ra được từ các biến quan sát là lãnh đạo thích nhân viên tự quyết định và phản hồi cho lãnh đạo hơn là hỏi ý kiến của họ (lãnh đạo); đồng thời không quá chú ý hoặc kiểm soát những chi tiết nhỏ nhặt.

\section{Bảng 4}

Mô tả các biến phong cách lãnh đạo tự do

\begin{tabular}{|l|c|c|c|}
\hline & Trung bình & STD & Kiểm định-t \\
\hline $\begin{array}{l}\text { Lãnh đạo tin tưởng rằng nhân viên sẽ có cách thức làm } \\
\text { việc tôt nhất trong môi trường khi chỉ nhận được sự } \\
\text { hướng dẫn ít nhất }\end{array}$ & 3,24 & 1,13 & $2,99 * * *$ \\
\hline $\begin{array}{l}\text { Lãnh đạo tin rằng nhân viên trong cơ quan sẽ không } \\
\text { có gì ngạc nhiên khi Ông/bà ta để cho nhân viên tự } \\
\text { làm việc độc lập }\end{array}$ & 3,49 & 1,09 & $6,23 * * *$ \\
\hline $\begin{array}{l}\text { Lãnh đạo không quá chú ý hoặc kiểm soát những chi } \\
\text { tiết nhỏ nhặt }\end{array}$ & 3,38 & 1,05 & $5,05^{* * *}$ \\
\hline $\begin{array}{l}\text { Lãnh đạo thích nhân viên tự quyết định và phản hồi } \\
\text { cho lãnh đạo hơn là hỏi ý kiến của họ (lãnh đạo) }\end{array}$ & 3,48 & 1,07 & $6,18^{* * *}$ \\
\hline
\end{tabular}

Ghi chú: kiểm định $\mathrm{t}$ với giá trị $=3$. STD: độ lệch chuẩn

*,**,*** thể hiện mức có nghĩa thống kê theo thứ tự ở mức ý nghĩa $10 \%, 5 \%$, và $1 \%$

Nguồn: Kết quả phân tích dữ liệu của nhóm nghiên cứu

Từ kết quả phân tích thống kê mô tả, tổng hợp ý kiến đánh giá về phong cách lãnh đạo tại các cơ quan hành chính quận Bình Thủy được trình bày trong Bảng 5 cho thây: lãnh đạo dân chủ là phong cách phổ biến nhất trong hệ thống với điểm trung bình là 3,59 , kế đến là phong cách tự do (3,40 điểm). Phong cách độc tài ít được thể hiện với điểm trung bình là 2,78. Xếp hạng thứ 3 là phong cách gia trưởng. Theo phong cách dân chủ thì sự vắng mặt của người lãnh 
đạo không ảnh hưởng lớn đến công việc hàng ngày tại cơ quan, vì các nhóm nhân viên có tinh thần làm việc độc lập, tự chủ theo công việc đã tự nhận và được xem là phong cách lãnh đạo rất hiệu quả, đứng sau tự do và gia trưởng. Với phong cách này cho thấy các lãnh đạo đơn vị dường như đã chiếm được lòng trung thành của nhân viên.

\section{Bảng 5}

Phong cách lãnh đạo tại cơ quan hành chính quận Bình Thủy

\begin{tabular}{lcccc}
\hline Phong cách lãnh đạo & Trung bình & Độ lệch chuẩn & Kiểm định t & Xếp hạng \\
\hline Phong cách độc tài & 2,78 & 0,81 & $-3,87 * * *$ & 4 \\
Phong cách dân chủ & 3,59 & 0,78 & $10,56 * * *$ & 1 \\
Phong cách gia trưởng & 3,13 & 0,76 & $2,31 * * *$ & 3 \\
Phong cách tự do & 3,40 & 0,84 & $6,55^{* * *}$ & 2 \\
\hline
\end{tabular}

Nguồn: Kết quả phân tích dữ liệu của nhóm nghiên cứu

\subsection{Tình trạng sức khỏe thể chất, tâm lý và xã hội của nhân viên}

\subsubsection{Sức khỏe thể chất của nhân viên}

Kết quả đánh giá cảm nhận tình trạng sức khỏe của nhân viên tại các đơn vị khảo sát được trình bày trong Bảng 6 cho thấy rằng nhân viên tự đánh giá họ có những dấu hiệu và cảm nhận sức khỏe đang ở tình trạng tốt. Các biến quan sát có số trung bình hơn 3 , và điểm trung bình chung là 3,73. Đặc biệt có khoảng $75 \%$ đến $85 \%$ nhân viên báo cáo ít khi và chưa bao giờ có triệu chứng cao huyết áp, mỡ trong máu cao, các triệu chứng buồn nôn, chóng mặt. Cronbach's $\alpha=0,65$.

\section{Bảng 6}

Đánh giá cảm nhận tình trạng sức khỏe thể chất của nhân viên

\begin{tabular}{|c|c|c|c|c|c|c|c|c|}
\hline Biến quan sát & $\mathbf{A}$ & $\mathbf{F}$ & O & $\mathbf{S}$ & $\mathbf{N}$ & TB & STD & $\begin{array}{l}\text { Kiểm } \\
\text { định-t }\end{array}$ \\
\hline \multirow{2}{*}{$\begin{array}{l}\text { Anh/chị có bị huyết áp cao/ } \\
\text { cholesterol cao (mỡ trong } \\
\text { máu cao)/ bị bệnh cao huyết } \\
\text { áp? }\end{array}$} & 1 & 8 & 42 & 48 & 494 & \multirow[b]{2}{*}{4,17} & \multirow[b]{2}{*}{0,94} & \multirow[b]{2}{*}{17,22} \\
\hline & 0,52 & 4,15 & 21,76 & 24,87 & 48,70 & & & \\
\hline \multirow{2}{*}{$\begin{array}{l}\text { Anh/chị có thường dễ bị cảm } \\
\text { lạnh hoặc cảm cúm không? }\end{array}$} & 4 & 16 & 90 & 76 & 7 & \multirow{2}{*}{3,34} & \multirow{2}{*}{0,77} & \multirow{2}{*}{6,18} \\
\hline & 2,07 & 8,29 & 46,63 & 39,38 & 3,63 & & & \\
\hline \multirow{2}{*}{$\begin{array}{l}\text { Anh/chị có khi nào cảm thấy } \\
\text { bị buồn nôn hoặc bị ngất? }\end{array}$} & 3 & 4 & 31 & 68 & 87 & \multirow{2}{*}{4,20} & \multirow{2}{*}{0,89} & \multirow{2}{*}{18,70} \\
\hline & 1,55 & 2,07 & 16,06 & 35,23 & 45,08 & & & \\
\hline \multirow{3}{*}{$\begin{array}{l}\text { Anh/chị có cảm thấy thở gấp } \\
\text { khi đi lên cầu thang bộ } \\
\text { không? }\end{array}$} & 3 & 24 & 66 & 75 & 25 & \multirow[b]{2}{*}{3,49} & \multirow[b]{2}{*}{0,92} & \multirow[b]{2}{*}{7,39} \\
\hline & 1,55 & 12,44 & 34,20 & 38,86 & 12,95 & & & \\
\hline & 2 & 8 & 93 & 81 & 9 & 3,45 & 0,70 & 8,96 \\
\hline
\end{tabular}




\begin{tabular}{|c|c|c|c|c|c|c|c|c|}
\hline Biến quan sát & $\mathbf{A}$ & $\mathbf{F}$ & $\mathbf{O}$ & $\mathbf{S}$ & $\mathbf{N}$ & $\mathbf{T B}$ & $\mathbf{S T D}$ & $\begin{array}{l}\text { Kiểm } \\
\text { định-t }\end{array}$ \\
\hline $\begin{array}{l}\text { Anh/chị thường cảm thấy } \\
\text { mệt mỏi trong lúc làm việc } \\
\text { không? }\end{array}$ & 1,04 & 4,15 & 48,19 & 41,97 & 4,66 & & \\
\hline
\end{tabular}

Ghi chú: $\mathrm{A}$ (rất thường xuyên), $\mathrm{F}$ (thường xảy $\mathrm{ra}$ ), $\mathrm{O}$ (bình thường), $\mathrm{S}$ (ít khi), $\mathrm{N}$ (chưa bao giờ)

TB: trung bình. STD: độ lệch chuẩn. Hàng trên: số nhân viên; hàng dưới: tỷ lệ (\%)

Nguồn: Kết quả phân tích dữ liệu của nhóm nghiên cứu

\subsubsection{Sức khỏe tâm lý của nhân viên}

Sức khỏe tâm lý hay tình trạng tâm lý tốt là một trong những đặc điểm của một người có sức khỏe tốt như đã định nghĩa trong phần 2 . Kết quả khảo sát cho thấy tình trạng tâm lý của nhân viên làm việc tại các đơn vị hành chính quận Bình Thủy cũng có mức độ khá tốt. Trung bình của các biến là trên 3 , và trung bình chung là 4,07 . Hơn $86 \%$ số nhân viên được khảo sát cho biết rất ít khi và hầu như chưa bao giờ có tình trạng rất khó để ngủ hoặc ngủ không yên giấc vào ban đêm. Điều này cũng khá phù hợp với đặc điểm nhân chủng học của mẫu là độ tuổi của nhân viên khảo sát là khá trẻ, hơn $83 \%$ nhân viên được khảo sát có độ tuổi dưới 40 . Tình trạng yếu sinh lý, than thở phàn nàn về chuyện trong quá khứ, cũng như không thể tập trung trong công việc và cảm thấy buồn vào buổi sáng chiếm tỷ lệ ít hơn $10 \%$ nhân viên. Cronbach's $\alpha$ thang đo $=0,66$.

\section{Bảng 7}

Đánh giá cảm nhận tình trạng sức khỏe tâm lý của nhân viên

\begin{tabular}{|c|c|c|c|c|c|c|c|c|}
\hline Biến quan sát & $\mathbf{A}$ & $\mathbf{F}$ & $\mathbf{O}$ & $\mathbf{S}$ & $\mathbf{N}$ & TB & STD & $\begin{array}{l}\text { Kiểm } \\
\text { định-t }\end{array}$ \\
\hline \multirow{2}{*}{$\begin{array}{l}\text { Anh/chị thường dành quá } \\
\text { nhiều thời gian để than thở, } \\
\text { phàn nàn về chuyện quá } \\
\text { khứ? }\end{array}$} & 1 & 3 & 21 & 87 & 81 & \multirow[b]{2}{*}{4,26} & \multirow[b]{2}{*}{0,76} & \multirow[b]{2}{*}{23,25} \\
\hline & 0,52 & 1,55 & 10,88 & 45,08 & 41,97 & & & \\
\hline \multirow{2}{*}{$\begin{array}{l}\text { Anh/Chị đã từng có tình } \\
\text { trạng không thể tập trung } \\
\text { vào công việc mình đang } \\
\text { làm không? }\end{array}$} & - & 2 & 63 & 107 & 21 & \multirow[b]{2}{*}{3,76} & \multirow[b]{2}{*}{0,65} & \multirow[b]{2}{*}{16,29} \\
\hline & - & 1,04 & 32,64 & 55,44 & 10,88 & & & \\
\hline \multirow{2}{*}{$\begin{array}{l}\text { Anh/chị có tình trạng rất khó } \\
\text { để ngủ hoặc ngủ không yên } \\
\text { giấc vào ban đêm không? }\end{array}$} & 4 & 20 & 60 & 79 & 30 & \multirow[b]{2}{*}{3,58} & \multirow[b]{2}{*}{0,94} & \multirow[b]{2}{*}{8,46} \\
\hline & 2,07 & 10,36 & 31,09 & 40,93 & 15,54 & & & \\
\hline \multirow{2}{*}{$\begin{array}{l}\text { Anh/chị thường cảm thấy } \\
\text { buồn bã hoặc chán nản, đặc } \\
\text { biệt vào buổi sáng không? }\end{array}$} & 1 & 6 & 17 & 92 & 77 & \multirow[b]{2}{*}{4,23} & \multirow[b]{2}{*}{0,78} & \multirow[b]{2}{*}{21,99} \\
\hline & 0,52 & 3,11 & 8,81 & 47,67 & 39,90 & & & \\
\hline \multirow{2}{*}{$\begin{array}{l}\text { Anh/chị có đang trong tình } \\
\text { trạng sinh lý bị yếu không? }\end{array}$} & 1 & 4 & 22 & 35 & 131 & \multirow[b]{2}{*}{4,51} & \multirow[b]{2}{*}{0,82} & \multirow[b]{2}{*}{25,63} \\
\hline & 0,52 & 2,07 & 11,40 & 18,13 & 67,88 & & & \\
\hline
\end{tabular}

Ghi chú: $\mathrm{A}$ (rất thường xuyên), $\mathrm{F}$ (thường xảy $\mathrm{ra}$ ), $\mathrm{O}$ (bình thường), $\mathrm{S}$ (ít khi), $\mathrm{N}$ (chưa bao giờ)

TB: trung bình. STD: độ lệch chuẩn. Hàng trên: số nhân viên; hàng dưới: tỷ lệ (\%)

Nguồn: Kết quả phân tích dữ liệu của nhóm nghiên cứu 


\subsubsection{Súc khỏe xã hội của nhân viên}

Tình trạng sức khỏe xã hội của nhân viên qua khảo sát là rất tốt. Kết quả giá trị Cronbach's $\alpha$ là 0,73 . Hơn $90 \%$ chưa bao giờ hoặc ít khi không vui vẻ, thoải mái để làm việc với cách quản lý hiện nay tại đơn vị. Đồng thời có hơn $70 \%$ nhân viên cảm thấy mình đang trong tình trạng hạnh phúc, vui vẻ. $87 \%$ nhân viên ít khi và chưa bao giờ ganh tỵ với người khác khi họ có nhiệm vụ hoặc công viêc khác tốt hơn. Với trung bình thang đo là 4,14, có thể nói đánh giá của các nhân viên về mối quan hệ xã hội trong cơ quan là tốt.

\section{Bảng 8}

Đánh giá cảm nhận tình trạng sức khỏe xã hội của nhân viên

\begin{tabular}{|c|c|c|c|c|c|c|c|c|}
\hline Biến quan sát & $\mathbf{A}$ & $\mathbf{F}$ & $\mathbf{O}$ & $\mathbf{S}$ & $\mathbf{N}$ & TB & STD & $\begin{array}{l}\text { Kiểm } \\
\text { định-t }\end{array}$ \\
\hline \multirow{2}{*}{$\begin{array}{l}\text { Anh/chị có cảm thấy mình } \\
\text { đang trong tình trạng không } \\
\text { hạnh phúc }\end{array}$} & 5 & 8 & 28 & 74 & 78 & \multirow[b]{2}{*}{4.10} & \multirow[b]{2}{*}{0.97} & \multirow[b]{2}{*}{15.71} \\
\hline & 2,59 & 4,15 & 14,51 & 38,34 & 40,41 & & & \\
\hline \multirow{2}{*}{$\begin{array}{l}\text { Anh/chị lúc nào cũng cảm } \\
\text { thấy nóng nảy, bực tức, khó } \\
\text { chịu? }\end{array}$} & 1 & 5 & 62 & 109 & 16 & \multirow[b]{2}{*}{3,69} & \multirow[b]{2}{*}{0,68} & \multirow[b]{2}{*}{14,17} \\
\hline & 0,52 & 2,59 & 32,12 & 56,48 & 8,29 & & & \\
\hline \multirow{2}{*}{$\begin{array}{l}\text { Anh/chị thường cảm thấy } \\
\text { không vui vẻ, thoải mái để làm } \\
\text { việc với cách quản lý hiện nay } \\
\text { tại đơn vị? }\end{array}$} & 2 & 8 & 39 & 90 & 54 & \multirow[b]{2}{*}{3,96} & \multirow[b]{2}{*}{0,86} & \multirow[b]{2}{*}{15,53} \\
\hline & 1,04 & 4,15 & 20,21 & 46,63 & 27,98 & & & \\
\hline \multirow{2}{*}{$\begin{array}{l}\text { Anh/chị có ganh tỵ với người } \\
\text { khác khi họ có một công việc } \\
\text { tốt hơn không? }\end{array}$} & - & 4 & 19 & 54 & 116 & \multirow[b]{2}{*}{4,46} & \multirow[b]{2}{*}{0,76} & \multirow[b]{2}{*}{26,82} \\
\hline & - & 2,07 & 9,84 & 27,98 & 60,10 & & & \\
\hline \multirow{2}{*}{$\begin{array}{l}\text { Anh/chị thường xung đột với } \\
\text { đồng nghiệp của mình }\end{array}$} & - & 4 & 11 & 71 & 107 & \multirow[b]{2}{*}{4,46} & \multirow[b]{2}{*}{0,70} & \multirow[b]{2}{*}{28,93} \\
\hline & - & 2,07 & 5,70 & 36,79 & 55,44 & & & \\
\hline
\end{tabular}

Ghi chú: $\mathrm{A}$ (rất thường xuyên), $\mathrm{F}$ (thường xảy ra), $\mathrm{O}$ (bình thường), $\mathrm{S}$ (ít khi), $\mathrm{N}$ (chưa bao giờ)

TB: trung bình. STD: độ lệch chuẩn. Hàng trên: số nhân viên; hàng dưới: tỷ lệ (\%)

Nguồn: Kết quả phân tích dữ liệu của nhóm nghiên cứu

\subsubsection{Phân tích chi tiết sức khỏe thể chất, tâm lý và xã hội của nhân viên}

Kết quả so sánh sức khỏe thể chất, tâm lý, và xã hội theo thuộc tính của nhân viên (kiểm định $\mathrm{t}$ ) được trình bày trong Bảng 9 . Khi phân chia đối đượng khảo sát thành hai nhóm làm việc tại các UBND xã và nhóm UBND quận/phòng ban, kết quả phân tích cho thấy không có sự khác biệt về đánh giá tình trạng sức khỏe giữa hai nhóm nhân viên làm việc tại các UBND xã và nhóm UBND quận/phòng ban. Nói chung sức khỏe thể chất của các nhân viên cấp xã hoặc quận đều được cảm nhận là tốt. Sức khỏe tâm lý của hai nhóm nhân viên là không có sự khác biệt về mặt thống kê. Riêng yếu tố xã hội có sự khác biệt giữa 2 nhóm nhân viên. Nhân viên làm việc tại cấp xã có tình trạng sức khỏe xã hội tốt hơn, môi trường làm việc thoải mái hơn đối với nhân viên làm việc tại cẩp quận/phòng ban. 
Tương tự như vậy, phân tích theo nam và nữ thì không có sự khác biệt trong đánh giá cảm nhận về sức khỏe thể chất, tâm lý và xã hội. Cả nam và nữ cảm nhận có sức khỏe tương tự nhau dưới phong cách lãnh đạo hiện tại của thủ trưởng đơn vị.

Đánh giá cảm nhận của nhân viên và cấp phó về tình trạng sức khỏe cho thấy không có sự khác biệt về sức khỏe thể chất và xã hội. Yếu tố tâm lý có khác nhau giữa cấp phó và nhân viên. Cấp nhân viên có tình trạng tâm lý tốt hơn so với cấp phó. Sự khác biệt này có nghĩa ở mức $5 \%$. Điều này có thể hiểu là do cấp phó là người giúp việc cho thủ trưởng, và áp lực công việc nhiều, dễ dẫn đến tình trạng mệt mỏi, khó ngủ và căng thẳng vào các buổi sáng đầu giờ làm việc.

Phân tích trong phần 4.3 cho thấy phong cách lãnh đạo thể hiện rõ nét của trưởng đơn vị tại các cơ quan hành chính quận Bình Thủy là phong cách dân chủ và tự do. Kết quả phân tích đánh giá sức khỏe thể chất, tâm lý và xã hội của nhân viên cho thấy nhìn chung đều tốt, tất cả đều trên mức trung bình. Đặc biệt sức khỏe tâm lý và xã hội được đánh giá là khá tốt so với sức khỏe thể chất.

\section{Bảng 9}

Sức khỏe thể chất, tâm lý và xã hội của nhân viên (phân theo các thuộc tính)

\begin{tabular}{|c|c|c|c|c|c|c|}
\hline Sức khỏe & Đặc tính & Số mẫu & Trung bình & STD & Kiểm định t & $\begin{array}{l}\text { Mức ý } \\
\text { nghĩa }\end{array}$ \\
\hline \multirow[t]{2}{*}{ Thể chất } & Phòng ban & 96 & 3,68 & 0,58 & \multirow{2}{*}{$-1,38$} & \multirow{2}{*}{0,17} \\
\hline & UBND xã & 97 & 3,79 & 0,50 & & \\
\hline \multirow[t]{2}{*}{ Tâm lý } & Phòng ban & 96 & 4,05 & 0,58 & \multirow{2}{*}{$-0,43$} & \multirow{2}{*}{0,67} \\
\hline & UBND xã & 97 & 4,08 & 0,45 & & \\
\hline \multirow[t]{2}{*}{ Xã hội } & Phòng ban & 96 & 4,04 & 0,60 & \multirow{2}{*}{$-2,44$} & \multirow{2}{*}{0,02} \\
\hline & UBND xã & 97 & 4,23 & 0,49 & & \\
\hline \multirow[t]{2}{*}{ Thể chất } & Nam & 87 & 3,73 & 0,51 & \multirow{2}{*}{$-0,01$} & \multirow{2}{*}{0,99} \\
\hline & Nữ & 106 & 3,73 & 0,57 & & \\
\hline \multirow[t]{2}{*}{ Tâm lý } & Nam & 87 & 4,10 & 0,44 & \multirow{2}{*}{0,76} & \multirow{2}{*}{0,45} \\
\hline & Nữ & 106 & 4,04 & 0,58 & & \\
\hline \multirow[t]{2}{*}{ Xã hội } & Nam & 87 & 4,15 & 0,54 & \multirow{2}{*}{0,28} & \multirow{2}{*}{0,78} \\
\hline & Nữ & 106 & 4,12 & 0,57 & & \\
\hline \multirow[t]{2}{*}{ Thể chất } & Cấp phó & 41 & 3,65 & 0,54 & \multirow{2}{*}{$-1,04$} & \multirow{2}{*}{0,30} \\
\hline & Nhân viên & 152 & 3,75 & 0,55 & & \\
\hline \multirow[t]{2}{*}{ Tâm lý } & Cấp phó & 41 & 3,90 & 0,52 & \multirow{2}{*}{$-2,34$} & \multirow{2}{*}{0,02} \\
\hline & Nhân viên & 152 & 4,11 & 0,51 & & \\
\hline \multirow[t]{2}{*}{ Xã hội } & Cấp phó & 41 & 4,02 & 0,62 & \multirow{2}{*}{$-1,31$} & \multirow{2}{*}{0,19} \\
\hline & Nhân viên & 152 & 4,16 & 0,53 & & \\
\hline
\end{tabular}

Nguồn: Kết quả phân tích dữ liệu của nhóm nghiên cứu

Kết quả phân tích tương quan Pearson trình bày trong Bảng 10 cho thấy không có sự quan hệ giữa phong cách lãnh đạo độc tài đến sức khỏe thể chất, tâm lý và xã hội của nhân viên. Mặc dù có mối quan hệ tích cực (dương) đến tình trạng sức khỏe nhưng tất cả các kiểm định về hệ số tương quan Pearson đều không có ý nghĩa thống kê ở mức $5 \%$. 
Phong cách lãnh đạo dân chủ, là một phong cách được nhân viên đánh giá là được lãnh đạo của họ thực hành trong việc quản lý nhân viên hiện nay, đều có tác động tốt đến 3 trạng thái của vấn đề sức khỏe là thể chất, tâm lý và xã hội. Hệ số tương quan Pearson đều có ý nghĩa ở mức 5\% đến $1 \%$. Đặc biệt, chính phong cách dân chủ có ảnh hưởng tích cực đến quan hệ xã hội, tinh thần thoải mái của nhân viên tại cơ quan.

Hai phong cách lãnh đạo còn lại là phong cách gia trưởng và tự do, đều không có mối quan hệ có ý nghĩa thống kê, mặc dù có mối quan hệ thuận chiều.

\section{Bảng 10}

Tương quan giữa phong cách lãnh đạo và sức khỏe thể chất, tâm lý, xã hội

\begin{tabular}{llll}
\hline Phong cách lãnh đạo & Thể chất & Tâm lý & Xã hội \\
\hline Độc tài & 0,133 & 0,081 & 0,089 \\
Dân chủ & $\mathbf{0 , 1 6 7 * *}$ & $\mathbf{0 , 1 7 1 * *}$ & $\mathbf{0 , 2 2 4 * * *}$ \\
Gia trưởng & 0,017 & 0,025 & 0,074 \\
Tự do & 0,057 & 0,095 & 0,035 \\
\hline
\end{tabular}

Ghi chú: **,*** thể hiện mức có nghĩa thống kê theo thứ tự ở mức ý nghĩa $5 \%$, và $1 \%$

Nguồn: Kết quả phân tích dữ liệu của nhóm nghiên cứu nhân viên

\subsubsection{Anh hưởng của phong cách lãnh đạo đến sức khỏe thể chất, tâm lý và xã hội của}

Kết quả phân tích hồi quy OLS kiểm định 3 giả thuyết của nghiên cứu được trình bày tại Bảng 11. Kết quả kiểm định mức độ phù hợp, kiểm định $\mathrm{F}(4,192)=3,19 * *$ cho thấy các biến số độc lập có khả năng giải thích được mức độ ảnh hưởng của chúng với sự thay đổi trong đánh giá cảm nhận về thể chất, tâm lý và xã hội của nhân viên, mặc dù khả năng giải thích sự thay đổi này không lớn (giá trị $\mathrm{R}$ bình phương từ 0,21 đến 0,26 ). Điều này là hợp lý vì thể chất, tâm lý và tình trạng xã hội của một người không chỉ phụ thuộc duy nhất vào phong cách lãnh đạo của các nhà quản lý tại đơn vị, mà còn quyểt định bởi nhiều yếu tố khác (ví dụ: thói quen dinh dưỡng, giới tính, điều kiện sống, việc làm).

Kiểm định quan hệ cộng tuyến giữa các biến độc lập thông qua hệ số VIF và Tolerance cho thấy hiện tượng đa cộng tuyến không phải là vấn đề lớn trong mô hình (VIF <10). Mô hình không kiểm định tự tương quan do số liệu không phải dãy số thời gian mà là phỏng vấn các đối tượng trong cùng khoảng thời gian (số liệu cross sectional data). Kết quả phân tích đồ thị phần dư của cả 3 mô hình đều cho thấy phần dư được phân phối chuẩn với trung bình bằng zero và độ lệch chuẩn bằng 1 . Nói cách khác là mô hình hồi quy không vi phạm các giả định cơ bản của hồi quy OLS.

Kết quả trong Bảng 11 cũng cho thấy phong cách lãnh đạo dân chủ có ảnh hưởng tốt đến tình trạng thể chất, tâm lý và xã hội của nhân viên tương tự như kết quả hệ số tương quan Pearson. Tuy nhiên, trong mô hình 1, phong cách lãnh đạo độc tài cũng có ảnh hưởng đến sức khỏe thể chất (khác với kết quả tương quan). Sự khác biệt này là do có sự tương tác giữa các biến cùng ảnh hưởng. 


\section{Bảng 11}

Ảnh hưởng của phong cách lãnh đạo đến sức khỏe thể chất, tâm lý, và xã hội

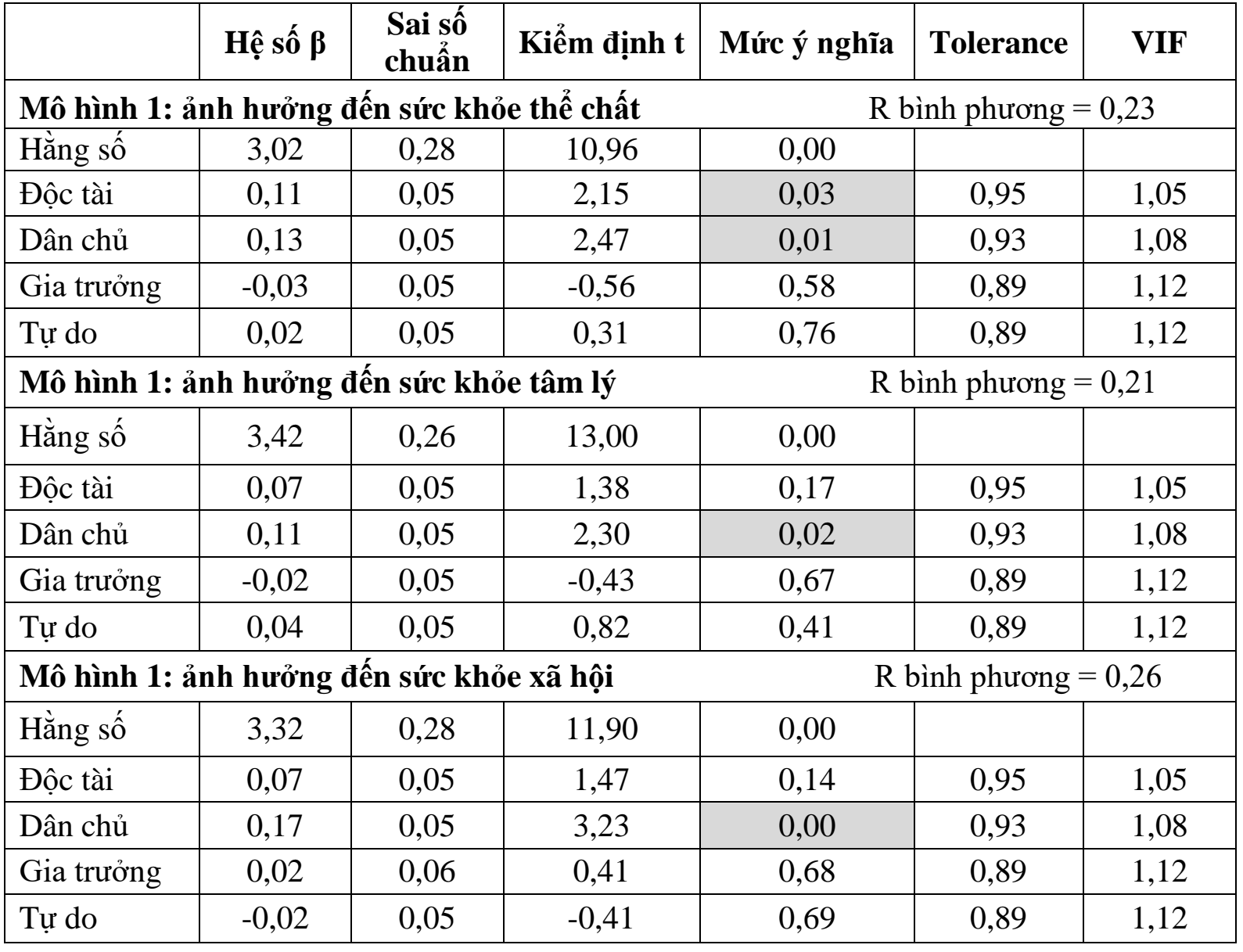

Nguồn: Kết quả phân tích dữ liệu của nhóm nghiên cứu

\section{Kết luận và hàm ý chính sách}

Kết quả phân tích cho thấy phong cách lãnh đạo dân chủ là phong cách phổ biến nhất trong hệ thống với điểm trung bình là 3,59 , kế đến là phong cách tự do $(3,4$ điểm). Phong cách độc tài ít được thể hiện với điểm trung bình là 2,78. Xếp hạng thứ 3 là phong cách gia trưởng.

Kết quả hồi quy ảnh hưởng của các phong cách lãnh đạo đến sức khỏe thể chất, tâm lý và xã hội cho thấy phong cách lãnh đạo dân chủ ảnh hưởng tốt đến cả 3 loại hình sức khỏe của nhân viên, và mô hình đáp ứng các yêu cầu kiểm định cơ bản về mức độ phù hợp, đa cộng tuyến, và phần dư được phân phối chuẩn.

Phong cách lãnh đạo dân chủ, là một phong cách được nhân viên đánh giá là được lãnh đạo của họ thực hành trong việc quản lý nhân viên hiện nay, đều có tác động tốt đến 3 trạng thái của vấn đề sức khỏe là thể chất, tâm lý và xã hội. Không có sự quan hệ giữa phong cách lãnh đạo độc tài đến sức khỏe thể chất, tâm lý và xã hội của nhân viên. Hai phong cách lãnh đạo còn lại là phong cách gia trưởng và tự do, cũng không có mối quan hệ có ý nghĩa thống kê, mặc dù có mối quan hệ thuận chiều. Có sự khác biệt có ý nghĩa thống kê về sức khỏe xã hội 
giữa khối nhân viên làm việc tại Phòng/Ban quận và nhân viên tại UBND xã; và khác biệt về sức khỏe tâm lý của cấp phó và nhân viên.

Từ những phân tích trên, đề tài đưa ra kiến nghị việc tăng cường, đào tạo cho nhà lãnh đạo về phong cách dân chủ và tự do là cần thiết, nhât là phong cách dân chủ. Với phong cách dân chủ, thủ trưởng các phòng ban và chủ tịch UBND các phường cần phải biết phân chia quyền lực quản lý của mình, tranh thủ ý kiến cấp dưới, đưa họ tham gia vào việc khởi thảo các quyết định.

Kết quả nghiên cứu này kỳ vọng chuyển đến các thủ trưởng văn phòng UBND, các phòng ban của quận và chủ tịch UBND các phường. Với mục đích cho thủ trưởng các đơn vị này nắm bắt được một cách chung nhất thực trạng các phong cách lãnh đạo mà họ đang áp dụng tại cơ quan đơn vị mà họ đang là thủ trưởng. Đồng thời chỉ ra cho các thủ trưởng đơn vị này thấy được những ảnh hưởng của các phong cách lãnh đạo của họ đến tình trạng thể chất, tâm lý và xã hội của các cán bộ, công chức làm việc tại các cơ quan đơn vị mình phụ trách.

\section{Tài liệu tham khảo}

Abu Mansor, N. N., Choon, M. W., Mohamed, A., \& Ishak, M. S. (2012). The relationship between management style and employees well-being: A case of non-managerial staffs. Procedia - Social and Behavioral Sciences, 40, 521-529.

Barzegar, M., Afzal, E., Tabibi, S. J., \& Delgoshaei, B. (2012). Relationship between leadership behavior, quality of work life and human resources productivity: Data from Iran. International Journal of Hospital Research 2012, 1(1), 1-14.

Beehr, T. A., \& Gupta, N. (1987). Organizational management styles, employee supervisory status, and employee responses. Human Relations, 40(1), 45-57. doi:10.1177/001872678704000104

Bennis, W. G. (1989). Managing the dream: Leadership in the $21^{\text {st }}$ century. Journal of Organizational Change Management, 2(1), 6-10.

Bennis, W. G. (1989). Trên bước đường trở thành nhà lãnh đạo [On the way to become a leader] (H. T. Vu, Trans.). Ho Chi Minh, Vietnam.

Bennis, W. G. (2013). The keys to effective leadership. In D. J. Weinfunter (Ed.), Second stage entrepreneurship: Ten proven strategies for driving aggressive growth (pp 171-188). New York, NY: Palgrave Macmillan Press.

Bennis, W. G., \& Nanus, B. (2007). Leaders: The strategies for taking charge. New York, NY: HarperCollins.

Bui, T. P. L. (2011). Anh hương của phong cách lãnh đạo với sự gắn kết đến tổ chức của nhân viên trong các ngân hàng thuơng mại cổ phần trên địa bàn TP.HCM [The influence of leadership style with employee's organizational commitment in joint stock commercial banks in Ho Chi Minh City]. (Doctoral dissertation). Đại học Kinh tế TP.HCM, Ho Chi Minh, Vietnam.

Ekin, K. P., \& Terri, A. S. (2008). Paternalistic Leadership: A review and agenda for future research. Journal of Management, 34(3), 566-593. doi:10.1177/0149206308316063 
Hoel, H., \& Cooper, C. (2000). Destructive conflict and bullying at work. Manchester, UK: Manchester School of Management.

Ibrahim, A. S., \& Al-Taneiji, S. (2013). Principal leadership style, school performance, and principal effectiveness in Dubai Schools. International Journal of Research studies in Education, 2(1), 41-54.

Kotter, J. P. (1990). A force for change: How leadership differs from management. New York, NY: The Free Press.

Nguyen, L. H. (2011). Nghệ thuật lãnh đạo [Art of leadership]. Hanoi, Vietnam: Nhà xuất bản Lao động - Xã hội.

Nielsen, K., Randall, R. J., Yarker, J., \& Brenner, S. (2008). The effects of transformational leadership on followers' perceived work characteristics and psychological well-being: A longitudinal study. Work and Stress, 22(1), 16-32. doi:10.1080/02678370801979430

Rus, M. (2012). Transformational leadership type in public and private organizations. European integration - Realities and perspectives. Retrieved March 20, 2013, from http://www.proceedings.univ-danubius.ro/index.php/eirp/article/view/1246

Smircich, L., \& Morgan, G. (1982). Leadership: The management of meaning. The Journal of Applied Behavioral Science, 18(3), 257-273.

Taleghani, G., Salmani, D., \& Taatian, A. (2010). Survey of leadership styles in different cultures. Iranian Journal of Management Studies (IJMS), 3(3), 91-111. doi:10.22059/IJMS.2011.21803

Tran, D. T. K., \& Nguyen, T. M. T. (2007). Ảnh hưởng của văn hóa tổ chức và phong cách lãnh đạo đến kết quả làm việc của nhân viên và lòng trung thành của ho đối với tổ chưc [The influence of organizational culture and leadership style on employees' performance and their loyalty to the organization]. Retrieved March 20, 2013, from http://digital.lib.ueh.edu.vn/handle/UEH/27788

Warrick, D. D. (1981). Leadership styles and their consequences. Journal of Experiential Learning and Simulation, 3(4), 155-172.

Winston, B. E., \& Patterson, K. (2006). An integrative definition of leadership international. Journal of Leadership Studies, 1(2), 6-66. 